\title{
Effects of insulin-like growth factor binding protein 3 on apoptosis of cutaneous squamous cell carcinoma cells
}

This article was published in the following Dove Press journal:

OncoTargets and Therapy

\author{
Jinli Liu ${ }^{1, *}$ \\ Yuanyuan Guo 2,* \\ Yuanyuna Huang ${ }^{3}$ \\ Haowei Xue ${ }^{4}$ \\ Suwen $\mathrm{Bai}^{2}$ \\ Jinhang Zhu ${ }^{2}$ \\ Xianming $\mathrm{Xia}^{3}$ \\ Bing Shen ${ }^{2}$ \\ Wei Fang \\ 'Department of Dermatology, Anhui \\ Provincial Hospital, Hefei 23000I, \\ Anhui, China; ${ }^{2}$ School of Basic \\ Medical Sciences, Anhui Medical \\ University, Hefei, Anhui 230032, China; \\ ${ }^{3}$ Department of Gastroenterology \\ and Hepatology, The Fourth \\ Affiliated Hospital of Anhui Medical \\ University, Hefei 230032, Anhui, China; \\ ${ }^{4}$ Department of Oral and Maxillofacial \\ Surgery, The First Affiliated Hospital \\ of Anhui Medical University, Hefei \\ 230022, Anhui, China; ${ }^{5}$ Department \\ of ICU, The Affiliated Hospital \\ of Qingdao University, Qingdao, \\ Shandong 26607I, China
}

*These authors contributed equally to this work

Correspondence: Wei Fang Department of ICU, The Affiliated Hospital of Qingdao University, 16 Jiangsu Road, Qingdao City, Shandong 26607I, China

Tel +86532 829l 2326

Email doctorfang@।63.com
Background: Cutaneous squamous cell carcinoma (CSCC) is the second most common carcinoma worldwide. Clinical treatment for patients with CSCC remains non-ideal. Insulin-like growth factor binding protein 3 (IGFBP3), a member of the insulin-like growth (IGF) system, participates in several biological processes, including cellular proliferation and apoptosis. Here, we explored the functional role of IGFBP3 in apoptosis and proliferation of A431 cells, a human CSCC cell line.

Materials and methods: Differential expression analysis, immunohistochemistry, immunoblotting, TUNEL assay, and CCK8 assay techniques were used to investigate the IGFBP3 expression levels in both A431 cells and CSCC tissue surgically obtained from humans as well as to explore the functional role of IGFBP3 in the apoptosis and proliferation of A431 cells Results: By using normal epidermal keratinocytes for comparison, we identified the top 10 ranked differentially upregulated genes expressed in human cutaneous squamous cell carcinoma cell lines. Among these 10 genes, IGFBP3 was ranked number 1. By using immunohistochemistry, we found that the expression level of IGFBP3 was significantly elevated in CSCC tissue compared with that in normal human skin tissue. Knockdown of IGFBP3 in A431 cells by transfection with IGFBP3-specific siRNA markedly altered the expression of proteins that contribute to apoptosis via mitochondrial pathways, significantly suppressing the expression of Bax and active caspase-3, while significantly increasing B-cell lymphoma-2 expression. TUNEL assay confirmed the effect of knockdown of IGFBP3 on the apoptosis as well. In addition, knockdown of IGFBP3 inhibited the proliferation of A431 cells.

Conclusion: IGFBP3 is overexpressed in both CSCC cell lines and tissue. Knockdown of IGFBP3 enhanced the apoptosis via a mitochondrial pathway and inhibited the proliferation of A431 cells. These findings indicate that IGFBP3 may be a biomarker and a potential therapeutic target for CSCC.

Keywords: CSCC, IGFBP3, proliferation, mitochondria

\section{Introduction}

Cutaneous squamous cell carcinoma (CSCC) is a malignant tumor originating from the keratinocytes of the epidermis or an appendage. ${ }^{1}$ It is the second most common carcinoma globally and is currently thought to be caused by excessive exposure to solar ultraviolet radiation, human papillomavirus, and immunosuppression. ${ }^{2-4}$ The incidence of CSCC shows a rising trend, especially among elderly white individuals, and CSCC is seriously harmful to health. ${ }^{5,6}$ Treatment of CSCC includes surgical resection, cryotherapy, photodynamic therapy, and radiotherapy. ${ }^{7}$ However, there remains a potential for CSCC to recur and metastasize, leading to high morbidity and mortality rates in these patients. ${ }^{8}$ 
Therefore, it is important to gain further insight into the pathogenesis of CSCC to develop better treatment methods. ${ }^{9}$

Increasing evidence indicates that the insulin-like growth factor (IGF) system is critical in the processes of tumor occurrence, development, and transformation. The IGF system comprises two peptides (IGF1 and IGF2), their receptors, and six IGF binding proteins (IGFBPs), of which IGFBP3 is the most abundant in the circulation and plays an essential role in regulating the IGF signaling pathways. ${ }^{10,11}$ Recent studies have shown that IGFBP3 sequesters IGF1 from its receptor to inhibit its action and to promote cell apoptosis of non-small cell lung cancer, colon cancer, breast cancer, esophageal cancer, and prostate cancer cells. ${ }^{12-16}$ Although IGFBPs have been shown to have IGF-independent actions, these activities are not well understood. ${ }^{11,17}$ Methylation of IGFBP3 inhibits its expression in colorectal, gastric, and breast carcinomas. ${ }^{18}$ Furthermore, there is evidence that a link between IGFBP3 and p53 increases apoptosis of cells. ${ }^{19}$ Conversely, it has been suggested that IGFBP3 induces growth factor- $\beta 1$ and epidermal growth factor receptor and leads to the proliferation of tumor cells. ${ }^{20,21}$ Studies have also demonstrated that glycosylation of IGFBP3 is closely correlated with the occurrence and development of breast cancer and is associated with a worse prognosis for patients with this disease. ${ }^{17}$ Furthermore, several studies have reported that the upregulation of IGFBP3 expression may be linked to lymph node metastasis of tumors. ${ }^{22,23}$ However, other studies have shown that IGFBP3 has dual functional effects on apoptosis and proliferation in malignant melanoma and astrocytoma. ${ }^{24,25}$ Consequently, the role of IGFBP3 in tumor development is complex and controversial and has thus become the focus of recent research. ${ }^{24}$ At present, little is known regarding its role in CSCC.

In this study, we first used the Gene Expression Omnibus (GEO) database developed by the National Center for Biotechnology Information (NCBI) to investigate differentially expressed genes (DEGs) in human CSCC cell lines. On the basis of our findings, we next explored the expression profile of IGFBP3 in CSCC tissue surgically derived from patients. Finally, we determined whether IGFBP3 played a functional role in apoptosis and proliferation in a human CSCC cell line (A431), which would suggest its potential use as a biomarker in the early diagnosis or treatment of CSCC.

\section{Materials and methods Materials}

Specific siRNAs for human IGFBP3 (5'-GCACAGAU ACCCAGAACUUUU-3') and scrambled siRNA (5'-UAA CGACGCGACGACGUAA-3') were designed and obtained from Biomics Biotechnologies Co., Ltd. (Nantong Shi, Jiangsu Sheng, China). Lipofectamine 3000 was purchased from Thermo Fisher Scientific (Waltham, MA, USA) for cell transfection. Anti- $\beta$-tubulin, anti-Bax, anti-caspase 3, anti-Bcell lymphoma-2 (Bcl-2), and anti-IGFBP3 primary antibodies were purchased from Bioss Biotechnology (Beijing, China).

\section{Microarray data}

The transcription profile of GSE66359 was downloaded from the NCBI GEO database (http://www.ncbi.nlm.nih. gov/geo/). The data included 13 samples from normal human epidermal keratinocytes ( $\mathrm{n}=5$, GSM1620805 to GSM1620809) and CSCC cell lines ( $\mathrm{n}=8$, GSM1620810 to GSM1620817).

\section{Differential gene expression analysis}

The Limma package in R software (http://www.r-project.org/) was used to conduct all statistical analyses. Upregulated and downregulated DEGs were defined and acquired as a foldchange threshold greater than 1.5. The R software was also used to perform a clustering analysis of the obtained DEGs and to generate a heat map.

\section{Cell culture and transfection}

The human CSCC cell line A431 (American Type Culture Collection [ATCC], Manassas, VA, USA) was cultured in Dulbecco's Modified Eagle's Medium (4.5 g/L glucose) supplemented with $10 \%$ fetal bovine serum, $100 \mathrm{U} / \mathrm{mL}$ penicillin, and $100 \mathrm{mg} / \mathrm{L}$ streptomycin in an incubator under conditions of saturated humidity, $37^{\circ} \mathrm{C}$, and $5 \%$ carbon dioxide. Cells in the logarithmic growth phase were used for experiments. The A431 cells in 12-well plates were transfected with IGFBP3 or with scrambled siRNA using Lipofectamine 3000 in medium without fetal bovine serum. Functional studies were conducted 48 hours after transfection.

\section{Western blotting}

Immunoblotting was performed as previously described. ${ }^{26}$ In brief, A431 cells were lysed using a detergent extraction buffer that contained $150 \mathrm{mmol} / \mathrm{L} \mathrm{NaCl}, 20 \mathrm{mmol} / \mathrm{L}$ Tris-HCl (pH 7.5), 1 mmol/L EDTA, 1 mmol/L EGTA, 1\% Nonidet P-40, $2.5 \mathrm{mmol} / \mathrm{L}$ sodium pyrophosphate, and 1\% sodium deoxycholate, as well as protease inhibitor cocktail tablets. Protein concentrations were determined using the Bradford assay. Extracted proteins were loaded onto 12\% sodium dodecyl sulfate polyacrylamide gel electrophoresis gels and separated using a voltage of $100 \mathrm{~V}$ for 1 hour. The separated proteins were transferred to polyvinylidene 
difluoride membranes. Non-specific sites were blocked using PBS with $0.1 \%$ Tween 20 and 5\% non-fat milk for 1 hour at room temperature on a rocking platform. Primary antibodies (IGFBP3: bs-1434R; Bcl-2: bs-0032R; Bax: bs-0127R; active caspase-3: bs-0081R; $\beta$-tubulin: bs-4511R; Bioss Company, 1:200) were incubated overnight at $4^{\circ} \mathrm{C}$. After washing with PBS, the membrane was incubated with horseradish peroxidase-conjugated secondary antibodies $(1: 1,000)$. Antibody binding was detected using an enhanced chemiluminescence system. The intensity of each band was analyzed and is represented as the relative intensity of the anti- $\beta$-tubulin antibody. The data were expressed in percentage of the intensity between targeted proteins divided by $\beta$-tubulin.

\section{Immunohistochemistry}

This study was approved by the Clinical Research Ethics Committee at Anhui Medical University. Each specimen was obtained from a patient who provided written informed consent. All procedures conformed to the Declaration of Helsinki and Good Clinical Practice. ${ }^{27,28}$

The surgically obtained human CSCC tissues were fixed with 4\% paraformaldehyde for 24-48 hours, dehydrated, embedded in paraffin, and sliced into $5-\mu \mathrm{m}$ thick sections. The sections were then deparaffinized and rehydrated using routine methods. Antigen retrieval was accomplished by heating the sections in citrate buffer solution $(0.01 \mathrm{M}$, $\mathrm{pH}$ 6.0) with a microwave oven. The sections were rinsed and then treated for 30 minutes with 3\% hydrogen peroxide in deionized water to remove endogenous peroxidase activity. Non-specific binding sites were blocked by incubating in 5\% normal goat serum for 30 minutes at room temperature. Afterward, the slides were incubated with rabbit anti-IGFBP3 primary antibody at $4^{\circ} \mathrm{C}$ overnight. After rinsing with $\mathrm{PBS}$, the slides were incubated with biotin-labeled goat anti-rabbit IgG secondary antibody. Streptavidin-horseradish peroxidase was applied at $37^{\circ} \mathrm{C}$ for 30 minutes. The sections were washed with PBS, incubated with diaminobenzidine for 10 minutes (the degree of staining was controlled by visualization under a light microscope), and then washed with distilled water. Hematoxylin was used to stain cell nuclei. Dehydration and clearing of tissue sections were conducted as needed using standard protocols. Brown particles stained in cells were regarded as positive for the presence of antibody. The primary antibody was replaced by normal rabbit serum to provide a negative control. The experiments were repeated in specimens from six patients, and the data were evaluated by pathologists of Anhui Provincial Hospital.

\section{TUNEL assay}

Experiments were performed according to our previous study. ${ }^{29}$ TUNEL signal was detected via a kit following the manufacturer's instructions. Images of TUNEL assay were captured using fluorescence microscopy, and the data were analyzed with ImageJ software.

\section{CCK8 assay}

According to the previous study, the viability of the A431 cells was identified by the CCK 8 assay. ${ }^{30}$ After the cells were transfected with scrambled or IGFBP3 siRNA for 48 hours, A431 cells were trypsinized and seeded into 96-well plates at an equal density of $6 \times 10^{3}$ cells/well. On the next day, $10 \mu \mathrm{L}$ of CCK8 was added to each well of the 96-well plate and incubated for 4 hours at $37^{\circ} \mathrm{C}$ with $5 \% \mathrm{CO}_{2}$. Eventually, the absorbance of the solution of each well was determined at a wavelength of $450 \mathrm{~nm}$. The cell viability is expressed as the absorbance value (optical density: OD).

\section{Statistical analysis}

We used SigmaPlot software (Systat Software Inc, San Jose, CA, USA) to perform unpaired, two-tailed Student's $t$-tests. All data are expressed as mean \pm standard error of the mean (SEM). $P<0.05$ was considered statistically significant.

\section{Results Identification of DEGs}

Microarray expression profiling was conducted using the GEO database to identify significant DEGs in CSCC cell lines compared with normal human epidermal keratinocytes. On the basis of a fold change greater than 1.5, we identified the top 10 upregulated DEGs (Figure 1A). Of these, IGFBP3 was ranked number one. Figure $1 \mathrm{~B}$ shows the heat map generated for the expression profiles of IGFBPs, bone marrow stromal protein 2 (BST2), and members of the melanoma antigen family A across different normal and CSCC cell samples.

\section{Enhanced expression of IGFBP3 in human CSCC tissue}

Because growing evidence has indicated that IGFBP3 is involved in the development of various cancers, including colon cancer, breast cancer, and malignant melanoma, ${ }^{13,14,24}$ we also investigated IGFBP3 expression in surgically obtained specimens from patients with CSCC. The results of our immunohistochemistry assays indicated that brown signal representing IGFBP3 protein was markedly stronger in the cells of CSCC tissue than that in the cells of normal skin tissue (Figure 2C-D). But the brown signals were not 
A

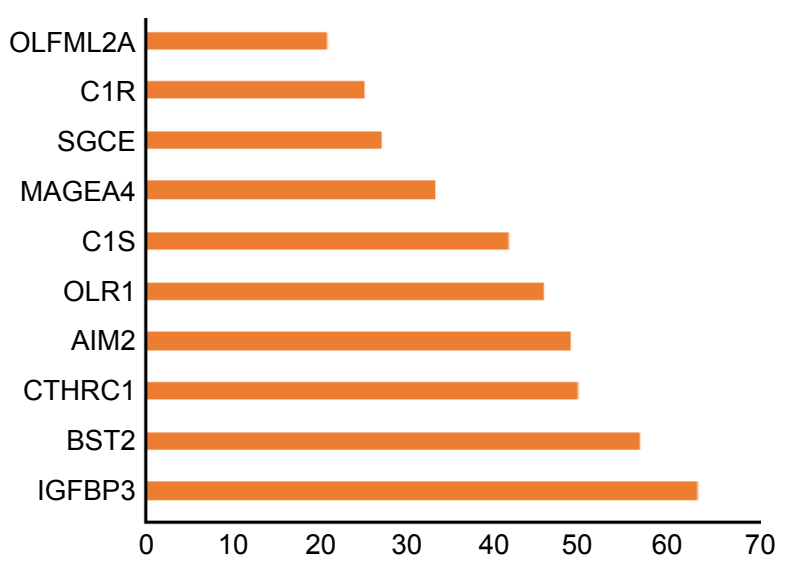

B

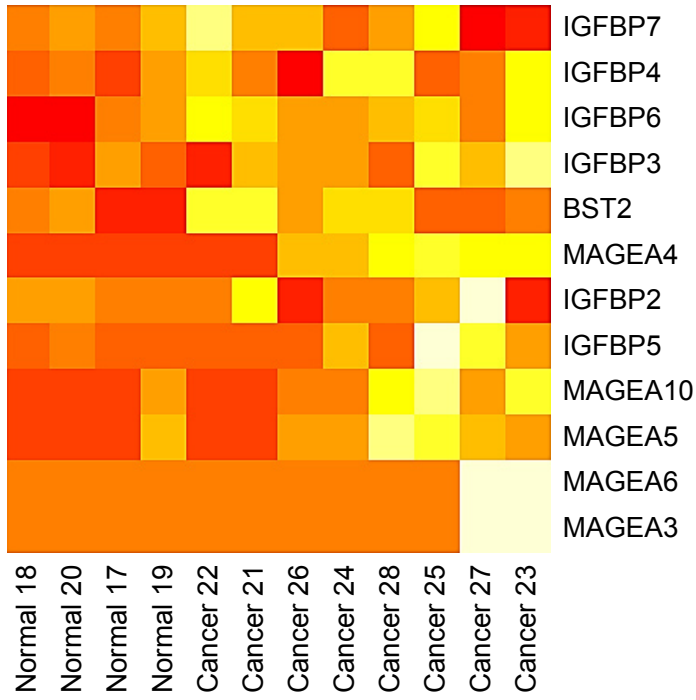

Figure I Rank order and heat map of genes differentially expressed in cutaneous squamous cell carcinoma cells vs normal human epidermal keratinocytes.

Notes: (A) The top 10 ranked differentially expressed upregulated genes. (B) Heat map showing the expression of those genes differentially expressed between normal human epidermal keratinocytes (normal) and cutaneous squamous cell carcinoma cells (cancer).

Abbreviations: AIM2, absent in melanoma 2; BST2, bone marrow stromal protein 2; CIR, complement component one subcomponent r; CIS, complement component one subcomponent s; CTHRCI, collagen triple helix repeat containing I; IGFBP, insulin-like growth factor binding protein; MAGEA, melanoma antigen family A; OLRI, oxidized low-density lipoprotein receptor I; OLFML2A, olfactomedin-like 2A; SGCE, epsilon-sarcoglycan gene.

found if the primary antibody was replaced by normal rabbit serum as the negative control (Figure $2 \mathrm{~A}$ and B). On the basis of this finding, we speculated that IGFBP3 may also contribute to the development of CSCC.
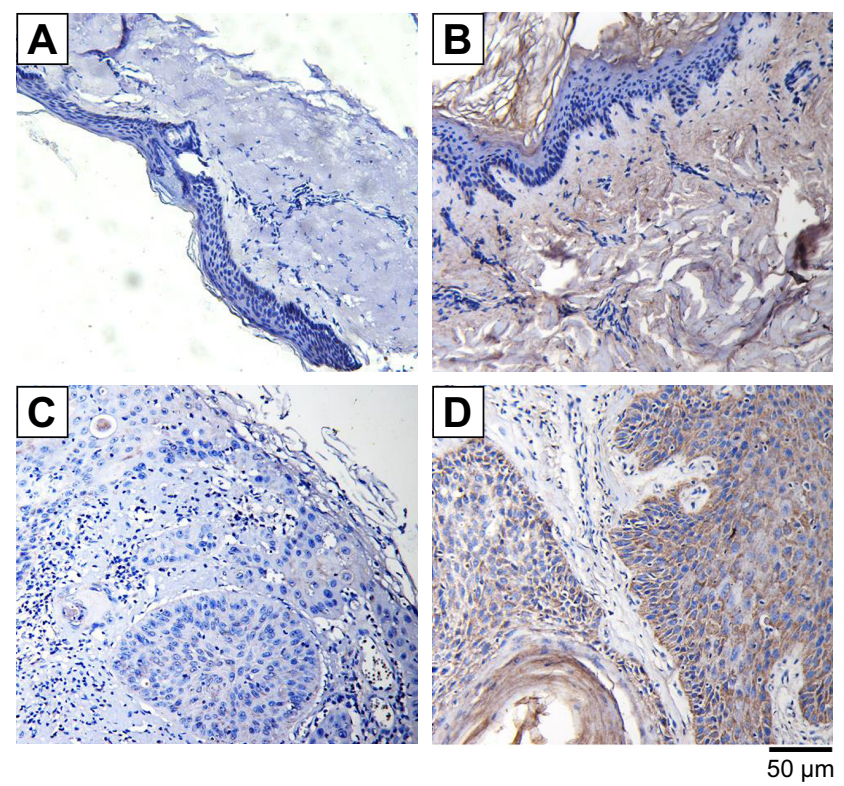

Figure 2 Expression levels of IGFBP3 in normal human skin and cutaneous squamous cell carcinoma tissues.

Notes: Immunohistochemically stained images showing the expression levels of IGFBP3 in normal human skin tissue $(\mathbf{A}, \mathbf{B})$ and cutaneous squamous cell carcinoma tissue (C, D). IGFBP3 protein shown in brown was recognized by an anti-IGFBP3 primary antibody. Nucleus is shown in blue (A, C). The primary antibody was replaced by normal rabbit serum to provide negative controls. Scale bar represents $50 \mu \mathrm{m}$.

Abbreviation: IGFBP3, insulin-like growth factor binding protein-3.

\section{Functional role of IGFBP3 in the apoptosis and proliferation of CSCC cells}

Recent studies have shown that IGFBP3 is a regulator of cancer cell apoptosis. ${ }^{12-16}$ To explore the functional role of IGFBP3 in the apoptosis of CSCC cells, we used IGFBP3specific siRNA to inhibit IGFBP3 expression. We first showed that compared with the expression of IGFBP3 following transfection of A431 cells with scrambled control siRNA, the expression of IGFBP3 following transfection with IGFBP3-specific siRNA was substantially reduced (Figure 3). Thus, we next used western blot assays to examine the change in the expression of apoptosis-related proteins. Our results indicated that IGFBP3 knockdown through transfection with IGFBP3-specific siRNA in A431 cells significantly suppressed the expression of Bax and active caspase-3, suggesting a pro-apoptotic effect; however, the expression of $\mathrm{Bcl}-2$, which is one of the most important antiapoptotic proteins, was significantly increased (Figure 4). To confirm our results further, we used TUNEL assay to detect apoptotic cells. Our data showed that IGFBP3 siRNA markedly enhanced the percentage of apoptotic A431 cells (Figure 5A and B). Moreover, the role of IGFBP3 in the proliferation of A431 cells was also investigated via CCK8 assay. We found that IGFBP3 siRNA significantly reduced A431 cell proliferation compared to scrambled siRNA control (Figure 5C). Together, these data suggested the involvement of IGFBP3 in apoptosis and proliferation of human CSCC A431 cells. 

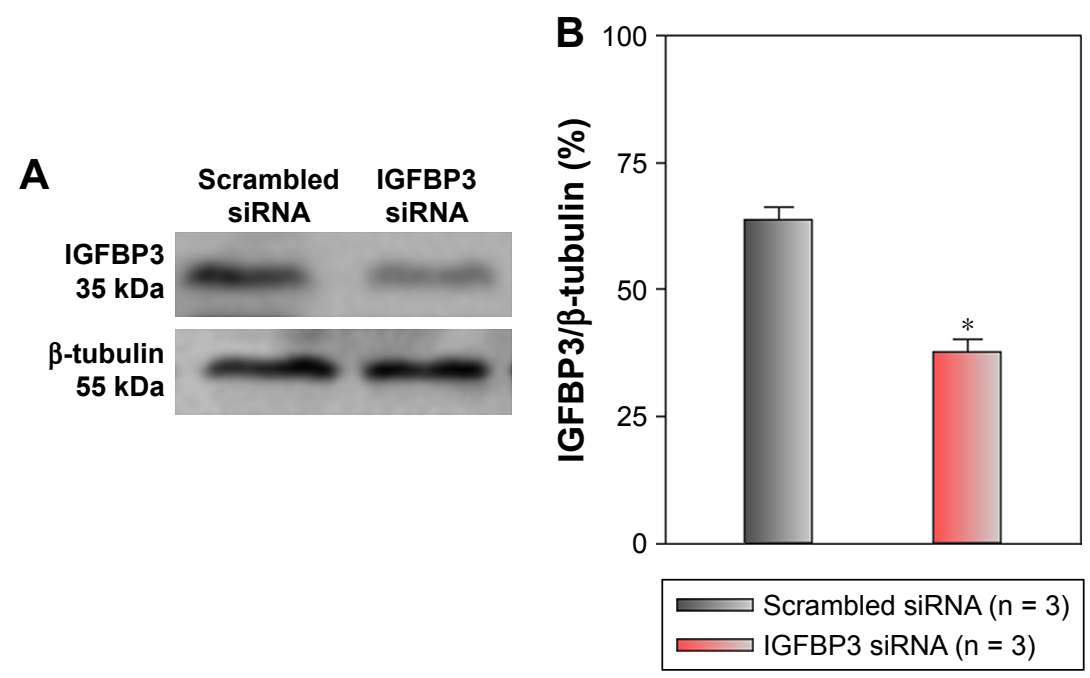

Figure 3 Effects of IGFBP3-specific siRNA on IGFBP3 expression in A43I cells.

Notes: Representative western blot images (A) and summary data (B) showing IGFBP3 protein expression levels in A43I cells transfected with scrambled or IGFBP3-specific siRNA. The OD of each protein was normalized to $\beta$-tubulin. Values shown are the mean \pm SEM $(n=3)$. *P $<0.05$ for scrambled siRNA vs IGFBP3-specific siRNA.

Abbreviations: IGFBP3, insulin-like growth factor binding protein-3; SEM, standard error of the mean.

A

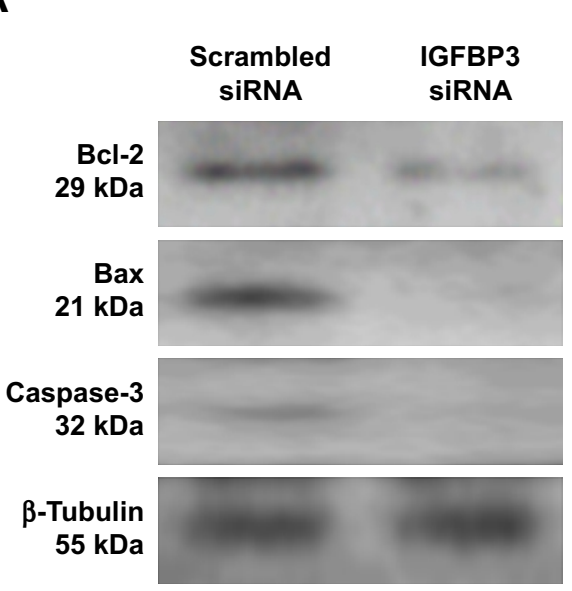

C

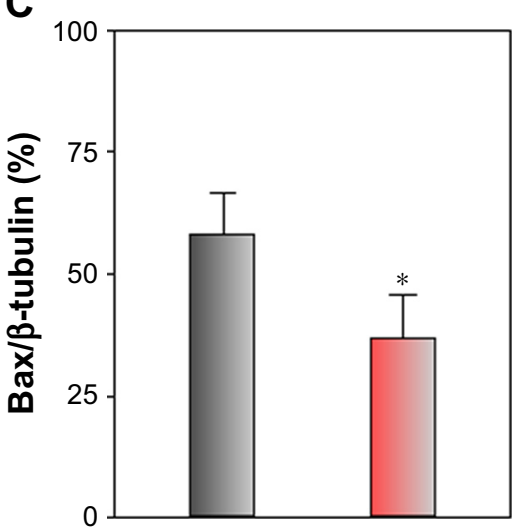

B
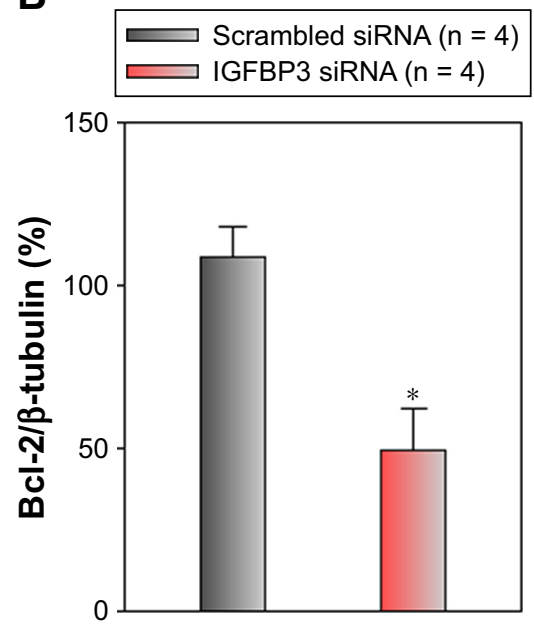

D

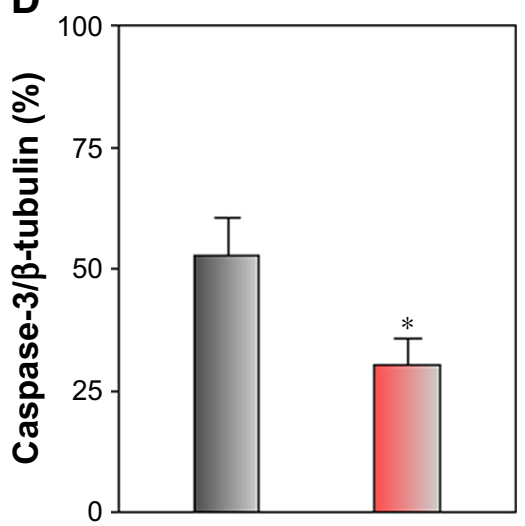

Ccrambled siRNA $(n=3) \rightleftharpoons \operatorname{IGFBP3} \operatorname{siRNA}(n=3)$

Figure 4 Effects of IGFBP3-specific siRNA on Bcl-2, Bax, and active caspase-3 expression levels in A43I cells.

Notes: Representative Western blot images and summary data showing Bcl-2 (A, B), Bax (A, C), and active caspase-3 (A, D) protein expression levels in A43I cells transfected with scrambled or IGFBP3-specific siRNA. The OD of each protein was normalized to $\beta$-tubulin. Values shown are the mean $\pm S E M(n=3-4)$. $* P<0.05$ for scrambled siRNA vs IGFBP3-specific siRNA.

Abbreviations: Bcl-2, B-cell lymphoma-2; IGFBP3, insulin-like growth factor binding protein-3; SEM, standard error of the mean. 
A

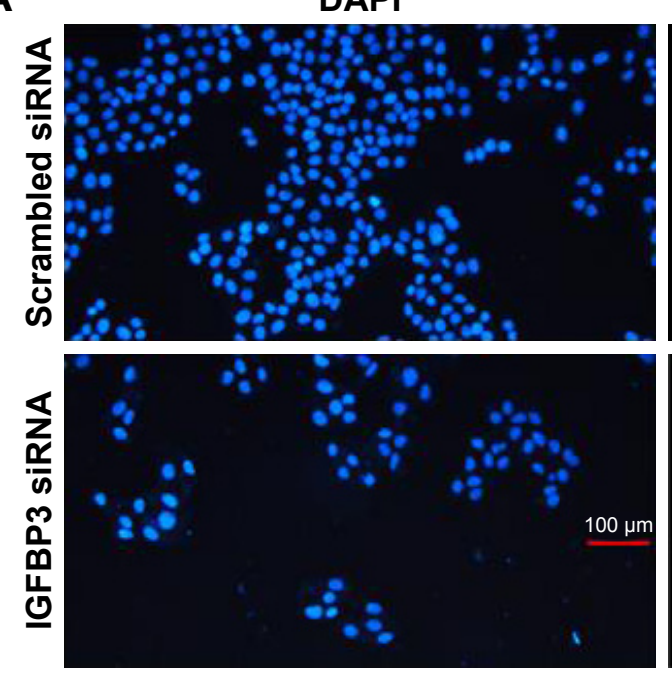

B

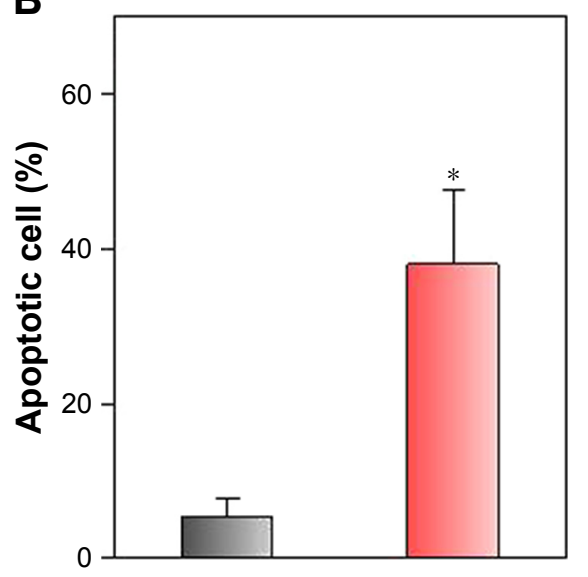

TUNEL


C

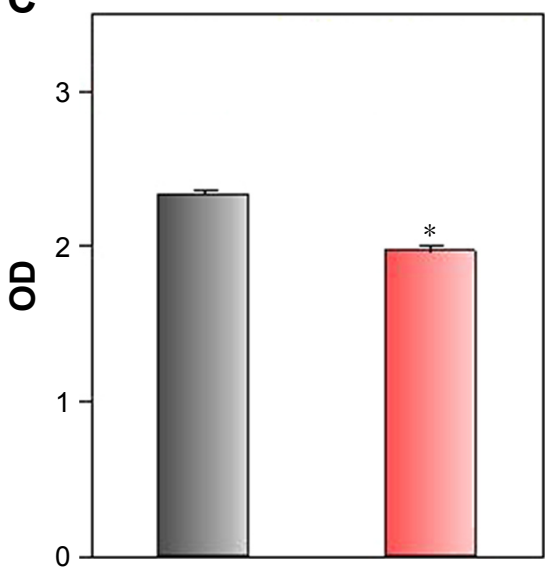

Scrambled siRNA $(n=5)$

IGFBP3 $(n=5)$

Figure 5 Effects of IGFBP3-specific siRNA on apoptosis and proliferation of A43I cells.

Notes: (A) Representative images showing the cellular nucleus (DAPI) and apoptotic cells (TUNEL). A43I cells were transfected with IGFBP3 or scrambled siRNA. (B) Summary data indicating the percentage of the apoptotic A43I cells. The percentage of the apoptotic A43I cells = apoptotic cell number/total cell number. (C) Cell viability representing OD value is expressed as the absorbance value. Values are shown as the mean $\pm S E$. $n=5$. $* P<0.05$ for scrambled siRNA vs IGFBP3-specific siRNA. Abbreviations: IGFBP3, insulin-like growth factor binding protein-3; SE, standard error.

\section{Discussion}

IGFBP3 plays complex roles in several types of cancers. However, the function of IGFBP 3 in the regulation of CSCC remains elusive. In this study, we investigated the expression profile of IGFBP3 in CSCC and the functional role of IGFBP3, a member of the IGF system, in the apoptosis and proliferation of A431 cells. We initially found that IGFBP3 expression was ranked first in the upregulated DEGs of CSCC cell lines compared with normal human epidermal keratinocytes. We next determined that compared with normal skin tissue, the expression level of IGFBP3 was enhanced in CSCC tissue. Finally, our results indicated that knockdown of IGFBP3 in a CSCC cell line significantly enhanced the apoptosis and proliferation.
CSCC is the second most common malignant neoplasm, and evidence indicates that its incidence is increasing. ${ }^{2,5,6}$ Unfortunately, CSCC has the potential to recur and metastasize following initial the treatment of the primary malignant neoplasm, leading to substantial morbidity and mortality. ${ }^{7,8}$ Thus, identification of the pathogenic mechanisms and discovery of novel treatment strategies, such as targeted therapy for CSCC, are critically important. ${ }^{9}$ IGFBP 3 is the most abundant IGFBP in the IGF system, which plays essential roles in regulating cell proliferation and apoptosis, even showing dual functional effects in several types of cancer cells. ${ }^{10,25}$ Of the top 10 ranked upregulated DEGs in CSCC cell lines (as defined by greater than 1.5-fold changes in expression levels), IGFBP3 was ranked highest. Our identification of 
the DEGs showed that the level of IGFBP3 expression was significantly increased in CSCC. To explore this finding further, we used surgically derived specimens from patients with CSCC and found that IGFBP3 was also elevated in these tissues, as indicated by immunohistochemical staining. This finding led us to believe that IGFBP3 may be associated with the regulation of CSCC. Apoptosis is a complex process that involves several signaling pathways. ${ }^{31,32}$ Cysteinyl aspartatespecific proteases (caspase) are key mediators of apoptosis, ${ }^{33}$ and caspase family members are classified as cytokine processors (caspase 1, 4, 5, 11, 12, 13, and 14), apoptotic initiators (caspase 2, 8, 9, and 10), and apoptotic executioners (caspase 3, 6, and 7). Caspase 3 is significantly associated with cell death via activation by initiators (mainly caspase 8 and 10). ${ }^{34}$ Members of the Bcl-2 family are also key apoptotic regulators, including anti-apoptotic proteins (mainly $\mathrm{Bcl}-2$ ) and pro-apoptotic proteins (mainly Bax). ${ }^{35}$ A variety of studies have demonstrated that IGFBP3 is involved with cell apoptosis and proliferation. ${ }^{12-16}$ Therefore, we explored the regulation of IGFBP3 in the apoptosis and proliferation of A431 cells. We found that IGFBP3 knockdown not only markedly increased the expression of Bcl-2 but also significantly suppressed the expression levels of Bax and active caspase 3. Moreover, TUNEL assay also confirmed that IGFBP3 siRNA markedly enhanced the apoptosis of A431 cells. On the other hand, we used CCK8 assay to find that IGFBP3 siRNA significantly inhibited the proliferation of A431 cells. These data indicated that IGFBP3 is involved in the apoptosis and proliferation of A431 cells and suggested that IGFBP3 may be a therapeutic target for CSCC.

Regarding the remaining top 10 upregulated DEGs in CSCC cells (shown in Figure 1A), we identified BST2, which is consistent with reports that it is overexpressed in breast cancer cells. ${ }^{36-38}$ Similarly, collagen triple helix repeat containing 1 was also identified and has been found to be induced in melanoma, colorectal cancer, and non-small cell lung cancer. ${ }^{39-41}$ However, the expression of absent in melanoma 2, which was also 1 of the top 10 DEGs in this study, is decreased in breast cancer and prostate cancer cells compared with normal cells. ${ }^{42,43}$ Oxidized low-density lipoprotein receptor 1 promotes cancer growth and migration and inhibits apoptosis. ${ }^{44,45}$ Melanoma antigen family A4 has important biological functions in the majority of serious carcinomas. ${ }^{46,47}$ Epsilon-sarcoglycan gene mutations cause neurological disorders such as myoclonus-dystonia syndrome. ${ }^{48}$ Olfactomedin-like $2 \mathrm{~A}$ is a senescence-specific gene and helps during chemotherapy of carcinoma. ${ }^{49} \mathrm{Com}-$ plement components $1 \mathrm{r}$ and $1 \mathrm{~s}$ are highly specific serine proteases that promote the progression and metastasis of melanoma, breast, lung, colon, and pancreatic cancers. ${ }^{50}$ All these genes and gene products warrant further investigation in future studies examining CSCC.

\section{Conclusion}

We demonstrated that IGFBP3 was upregulated in CSCC tissues and that knockdown of IGFBP3 enhanced the apoptosis via the mitochondrial pathway and inhibited proliferation of A431 cells. Taken together, our results suggest that IGFBP3 may be a biomarker and a potential therapeutic target for CSCC. However, the effect of IGFBP3 on the migration, invasion, and other progress of CSCC remains unknown. Further study will be required to determine the function of IGFBP3 in the regulation of CSCC.

\section{Acknowledgment}

This work was supported by grants from the National Natural Science Foundation of China (grant numbers U1732157, 81701879, and 81570403); National Training Program of Innovation and Entrepreneurship for Undergraduates (grant number 201610366003); Anhui Provincial Natural Science Foundation (grant number 1708085MH187); Anhui Medical University for Scientific Research (grant number BSKY XJ201607); and Outstanding Young Investigator of Anhui Medical University.

\section{Disclosure}

The authors report no conflicts of interest in this work.

\section{References}

1. Madan V, Lear JT, Szeimies RM. Non-melanoma skin cancer. Lancet. 2010;375(9715):673-685.

2. Parekh V, Seykora JT. Cutaneous Squamous Cell Carcinoma. Clin Lab Med. 2017;37(3):503.

3. Saladi RN, Persaud AN. The causes of skin cancer: a comprehensive review. Drugs Today. 2005;41(1):37.

4. Mittal A, Colegio OR. Skin Cancers in Organ Transplant Recipients. Am J Transplant. 2017;17(10):2509-2530.

5. Staples M, Marks R, Giles G. Trends in the incidence of non-melanocytic skin cancer (NMSC) treated in Australia 1985-1995: Are primary prevention programs starting to have an effect? Int J Cancer. 1998; 78(2):144-148.

6. Gray DT, Suman VJ, Su WP, et al. Trends in the population-based incidence of squamous cell carcinoma of the skin first diagnosed between 1984 and 1992. Arch Dermatol. 1997;133(6):735-740.

7. Alam M, Ratner D. Alam M, Ratner D. Cutaneous squamous-cell carcinoma. N Engl J Med. 2001;344344:975975-983983.

8. Garcia-Zuazaga J, Olbricht SM. Cutaneous squamous cell carcinoma. Adv Dermatol. 2008;24:33-57.

9. Kivisaari A, Kähäri VM. Squamous cell carcinoma of the skin: Emerging need for novel biomarkers. World J Clin Oncol. 2013;4(4):85-90.

10. Ranke MB. Insulin-like growth factor binding-protein-3 (IGFBP-3). Best Pract Res Clin Endocrinol Metab. 2015;29(5):701-711.

11. Butt AJ, Firth SM, King MA, Baxter RC. Insulin-like growth factorbinding protein-3 modulates expression of $\mathrm{Bax}$ and $\mathrm{Bcl}-2$ and potentiates p53-independent radiation-induced apoptosis in human breast cancer cells. J Biol Chem. 2000;275(50):39174. 
12. Georges RB, Adwan H, Hamdi H, et al. The insulin-like growth factor binding proteins 3 and 7 are associated with colorectal cancer and liver metastasis. Cancer Biol Ther. 2011;12(1):69-79.

13. Shiratsuchi I, Akagi Y, Kawahara A, et al. Expression of IGF-1 and IGF-1R and their relation to clinicopathological factors in colorectal cancer. Anticancer Res. 2011;31(7):2541-2545.

14. Yerushalmi R, Gelmon KA, Leung S, et al. Insulin-like growth factor receptor (IGF-1R) in breast cancer subtypes. Breast Cancer Res Treat. 2012;132(1):131-142.

15. Mccoll KE. Serum IGF-1 linking visceral obesity with esophageal adenocarcinoma: unconvincing evidence. Am J Gastroenterol. 2012; 107(2):205-206.

16. Daragó A, Sapota A, Matych J, et al. The correlation between zinc and insulin-like growth factor 1 (IGF-1), its binding protein (IGFBP-3) and prostate-specific antigen (PSA) in prostate cancer. Clin Chem Lab Med. 2011;49(10):1699.

17. Baricević I, Masnikosa R, Lagundžin D, Golubović V, Nedić O. Alterations of insulin-like growth factor binding protein 3 (IGFBP-3) glycosylation in patients with breast tumours. Clin Biochem. 2010; 43(9):725-731.

18. Tomii K, Tsukuda K, Toyooka S, et al. Aberrant promoter methylation of insulin-like growth factor binding protein-3 gene in human cancers. Int J Cancer. 2007;120(3):566-573.

19. Buckbinder L, Talbott R, Velasco-Miguel S, et al. Induction of the growth inhibitor IGF-binding protein 3 by p53. Nature. 1995; 377(6550):646-649.

20. Kansra S, Ewton DZ, Wang J, Friedman E. IGFBP-3 mediates TGF beta 1 proliferative response in colon cancer cells. Int J Cancer. 2000; 87(3):373.

21. Martin JL, de Silva HC, Lin MZ, Scott CD, Baxter RC. Inhibition of insulin-like growth factor-binding protein-3 signaling through sphingosine kinase-1 sensitizes triple-negative breast cancer cells to EGF receptor blockade. Mol Cancer Ther. 2014;13(2):316.

22. Zhong LP, Yang X, Zhang L, et al. Overexpression of insulin-like growth factor binding protein 3 in oral squamous cell carcinoma. Oncol Rep. 2008;20(6):1441.

23. Hansel DE, Rahman A, House M, et al. Met proto-oncogene and insulin-like growth factor binding protein 3 overexpression correlates with metastatic ability in well-differentiated pancreatic endocrine neoplasms. Clin Cancer Res. 2004;10(18 Pt 1):6152-6158.

24. Oy GF, Slipicevic A, Davidson B, et al. Biological effects induced by insulin-like growth factor binding protein 3 (IGFBP-3) in malignant melanoma. Int J Cancer. 2010;126(2):350-361.

25. Santosh V, Arivazhagan A, Sreekanthreddy P, et al. Grade-specific expression of insulin-like growth factor-binding proteins-2, -3 , and -5 in astrocytomas: IGFBP-3 emerges as a strong predictor of survival in patients with newly diagnosed glioblastoma. Cancer Epidemiol Biomarkers Prev. 2010;19(6):1399.

26. Ma Y, Zhang P, Li J, et al. Epoxyeicosatrienoic acids act through TRPV4-TRPC1-KCa1.1 complex to induce smooth muscle membrane hyperpolarization and relaxation in human internal mammary arteries. Biochim Biophys Acta. 2015;1852(3):552-559.

27. World Medical Association Declaration of Helsinki: ethical principles for medical research involving human subjects. JAMA. 2013;310(20):2191-2194.

28. Grimes DA, Hubacher D, Nanda K, et al. The Good Clinical Practice guideline: a bronze standard for clinical research. Lancet. 2005; 366(9480):172.

29. Xue H, Lu J, Yuan R, et al. Knockdown of CLIC4 enhances ATPinduced HN4 cell apoptosis through mitochondrial and endoplasmic reticulum pathways. Cell Biosci. 2016;6:5.
30. Kai S, Lei H, Wenxiu H, Bing S, Aman X. Chloride intracellular channel 4 protein promotes gastric cancer cell proliferation, invasion and migration. Int J Clin Exp Pathol. 2016;9:1770-1775.

31. Pertea M, Kim D, Pertea GM, Leek JT, Salzberg SL. Transcript-level expression analysis of RNA-seq experiments with HISAT, StringTie and Ballgown. Nat Protoc. 2016;11(9):1650.

32. Sarvothaman S, Undi RB, Pasupuleti SR, Gutti U, Gutti RK. Role in myeloid cell development. Apoptosis. 2015;50:73-79.

33. Nicholson DW, Thornberry NA. Caspases: killer proteases. Trends Biochem Sci. 1997;22(8):299-306.

34. Wolf BB, Green DR. Suicidal tendencies: apoptotic cell death by caspase family proteinases. J Biol Chem. 1999;274(29):20049-20052.

35. Wong WWL, Puthalakath $\mathrm{H}$. Bcl-2 family proteins: The sentinels of the mitochondrial apoptosis pathway. IUBMB Life. 2013;60(6):390-397.

36. Cai D, et al. Up-regulation of bone marrow stromal protein 2 (BST2) in breast cancer with bone metastasis. Bmc Cancer. 2009;9:1-10.

37. Yi EH, Yoo H, Noh KH, et al. BST-2 is a potential activator of invasion and migration in tamoxifen-resistant breast cancer cells. Biochem Biophys Res Commun. 2013;435(4):685-690.

38. Jones PH, Mahauad-Fernandez WD, Madison MN, Okeoma CM. BST-2/tetherin is overexpressed in mammary gland and tumor tissues in MMTV-induced mammary cancer. Virology. 2013;444(1-2):124.

39. Tang L, Dai DL, Su M, et al. Aberrant expression of collagen triple helix repeat containing 1 in human solid cancers. Clin Cancer Res. 2006; 12(12):3716-3722.

40. Kim HC, Kim YS, Oh HW, et al. Collagen triple helix repeat containing 1 (CTHRC1) acts via ERK-dependent induction of MMP9 to promote invasion of colorectal cancer cells. Oncotarget. 2014;5(2): 519-529.

41. Ke Z, He W, Lai Y, et al. Overexpression of collagen triple helix repeat containing 1 (CTHRC1) is associated with tumour aggressiveness and poor prognosis in human non-small cell lung cancer. Oncotarget. 2014;5(19):9410-9424.

42. Chen IF, Ou-Yang F, Hung JY, et al. AIM2 suppresses human breast cancer cell proliferation in vitro and mammary tumor growth in a mouse model. Mol Cancer Ther. 2006;5(1):1.

43. Ponomareva L, Liu H, Duan X, et al. AIM2, an IFN-inducible cytosolic DNA sensor, in the development of benign prostate hyperplasia and prostate cancer. Mol Cancer Res. 2013;11(10):1193-1202.

44. Hirsch HA, Iliopoulos D, Joshi A, et al. A transcriptional signature and common gene networks link cancer with lipid metabolism and diverse human diseases. Cancer Cell. 2010;17(4):348.

45. Khaidakov M, Mitra S, Kang BY, et al. Oxidized LDL receptor 1 (OLR1) as a possible link between obesity, dyslipidemia and cancer. PLoS One. 2011;6(5):e20277.

46. Dhodapkar MV, Osman K, Teruya-Feldstein J, et al. Expression of cancer/testis (CT) antigens MAGE-A1, MAGE-A3, MAGE-A4, CT-7, and NY-ESO-1 in malignant gammopathies is heterogeneous and correlates with site, stage and risk status of disease. Cancer Immun. 2003;3:9.

47. Yakirevich E, Sabo E, Lavie O, et al. Expression of the MAGE-A4 and NY-ESO-1 cancer-testis antigens in serous ovarian neoplasms. Clin Cancer Res. 2003;9(17):6453.

48. Peall KJ, Smith DJ, Kurian MA, et al. SGCE mutations cause psychiatric disorders: clinical and genetic characterization. Brain. 2013;136(Pt 1): 294-303.

49. Schwarze SR, Fu VX, Desotelle JA, Kenowski ML, Jarrard DF. The identification of senescence-specific genes during the induction of senescence in prostate cancer cells. Neoplasia. 2005;7(9):816.

50. Afshar-Kharghan V. The role of the complement system in cancer. J Clin Invest. 2017;127(3):780. 
OncoTargets and Therapy

\section{Publish your work in this journal}

OncoTargets and Therapy is an international, peer-reviewed, open access journal focusing on the pathological basis of all cancers, potential targets for therapy and treatment protocols employed to improve the management of cancer patients. The journal also focuses on the impact of management programs and new therapeutic agents and protocols on

patient perspectives such as quality of life, adherence and satisfaction The manuscript management system is completely online and includes a very quick and fair peer-review system, which is all easy to use. Visit http://www.dovepress.com/testimonials.php to read real quotes from published authors.

Submit your manuscript here: http://www.dovepress.com/oncotargets-and-therapy-journal 